\title{
Improvement of Sleep Quality after Surgical Decompression in Carpal Tunnel Syndrome
}

\author{
${ }^{1}$ Department of Neurology, Faculty of Medicine, University of \\ Medicine and Pharmacy at Ho Chi Minh city, Ho Chi Minh city, \\ Vietnam \\ 2 Department of Neurology, Children's Hospital No. 2, Ho Chi Minh \\ city, Vietnam \\ 3 Department of Upper Limb Surgery, Military Hospital 175, Ho Chi \\ Minh city, Vietnam \\ ${ }^{4}$ Department of Medical Statistics and Informatics, Faculty of Public \\ Health, University of Medicine and Pharmacy at Ho Chi Minh city, Ho \\ Chi Minh city, Vietnam
}

Nguyen Le Trung Hieu ${ }^{1,2}$ Nguyen Anh Sang ${ }^{3}$ Nguyen Lam Vuong ${ }^{4}$

\begin{abstract}
Address for correspondence Nguyen Lam Vuong, MD, University of Medicine and Pharmacy at Ho Chi Minh City, 217 Hong Bang, Ward 11, District 5, Ho Chi Minh City 700000, Vietnam (e-mail: nguyenlamvuong@ump.edu.vn).
\end{abstract}

Indian J Neurosurg 2023;12:59-63.

\begin{abstract}
Background Carpal tunnel syndrome (CTS) is the most common entrapment neuropathy which can cause severe sleep disturbance. Carpal tunnel release (CTR) is a choice for severe cases, which has shown to improve sleep quality, but the available evidence is limited. This study aimed to investigate the impact of CTR on sleep quality and hand symptoms and functions in patients with CTS.

Methods This was a prospective study in 2019-2020 on patients with CTS and poor sleep quality undergoing CTR. Patients were evaluated before and at 1,3 , and 12 months after CTR by the Pittsburgh sleep quality index (PSQI) and Boston carpal tunnel syndrome questionnaires.

Results There were 33 patients with 27 females (82\%) and a median age of 51 years.

\section{Keywords}

- Carpal tunnel syndrome

- Carpal tunnel release

- Pittsburgh Sleep Quality Index

- Boston Carpal Tunnel Syndrome Questionnaire

The median time of CTS diagnosis and having sleep disorder before CTR were 12 and 6 months, respectively. The outcomes significantly improved after CTR, with the median PSQI and Boston symptom and function scores reduced from 12, 33, and 23 before CTR to 9, 14, and 11 at 1 month; 7, 13, and 9 at 3 months; and 1, 11, and 8 at 12 months postoperatively, respectively. The correlations between the PSQI and Boston symptom and function scores were $>0.6$ at all time-points.

Conclusions Surgical decompression significantly improves sleep quality and the hand symptoms and functions in patients with CTS. Long-term evaluations are lacking and thus are required in future studies.
\end{abstract}

\section{Introduction}

Carpal tunnel syndrome (CTS), first described by Sir James Paget in $1854{ }^{1}{ }^{1}$ is the most common entrapment neuropathy of the upper extremity. This disease has been reported to affect mostly women. ${ }^{2}$ It is characterized by numbness, tingling, and pain in the median nerve distribution. ${ }^{3,4}$ Pain and numbness in
DOI https://doi.org/ $10.1055 / \mathrm{s}-0041-1741406$. ISSN 2277-954X. (c) 2021. Neurological Surgeons' Society of India. All rights reserved. This is an open access article published by Thieme under the terms of the Creative Commons Attribution-NonDerivative-NonCommercial-License, permitting copying and reproduction so long as the original work is given appropriate credit. Contents may not be used for commercial purposes, or adapted, remixed, transformed or built upon. (https://creativecommons.org/ licenses/by-nc-nd/4.0/)

Thieme Medical and Scientific Publishers Pvt. Ltd., A-12, 2nd Floor Sector 2, Noida-201301 UP, India 
nighttime has also been reported as common symptoms of CTS. Night waking with numbness due to wrist position is an important problem of CTS which hinders the ability to sleep well. ${ }^{3,5,6}$ Disrupted sleep is also common in patients with CTS, with approximately $80 \%$ of patients with CTS having nighttime waking due to numbness. ${ }^{7}$ Due to frequent nighttime awakening and fragmented sleep, CTS also increases daytime sleepiness and dysfunction. Thus, relief of nighttime symptoms plays a key role in the treatment of CTS. While most conservative treatments do not work well with CTS with severe manifestations (e.g., nighttime symptoms), surgery is necessary. Carpal tunnel release (CTR) has shown to improve sleep disturbance in patients with $\mathrm{CTS} ;{ }^{8-13}$ however, the available evidence is limited, as the number of reported studies as well as their sample sizes are small. Therefore, we performed this study in order to investigate the impact of CTR on sleep quality and the symptoms and functions of the hand in patients with CTS and poor sleep quality.

\section{Methods}

\section{Study Design and Population}

This was a prospective study from May 2019 to September 2020 at a tertiary referral hospital in Ho Chi Minh city, Vietnam. The study was approved by an Independent Ethics Committee before recruiting any patient. We consecutively recruited patients older than 18 years of age with confirmed diagnosis of CTS who underwent CTR with existing preoperative diagnoses of poor sleep quality. Exclusion criteria were as follows: (1) comorbidities of other neurological diseases such as polyneuritis and brachial plexus disorders, and (2) lost to follow-up at all scheduled visit after the surgery. The diagnosis of CTS was in accordance with the clinical practice guideline approved by the American Academy of Orthopaedic Surgeons. ${ }^{14,15}$ Patients were diagnosed with poor sleep quality preoperatively when the global Pittsburgh sleep quality index (PSQI) score was more than five. The indications of surgery for patients with CTS included the denervation of the abductor pollicis brevis muscle, sensory loss, or pain unresponsive to conservative treatments. Written informed consent was obtained from all patients before enrollment.

\section{Assessment and Follow-Up of Patients}

Demographic, clinical data, PSQI, and the Boston carpal tunnel syndrome questionnaire were used to assess the function and severity of the disease preoperatively. All patients underwent median nerve decompression through a limited palmar incision by a single experienced surgeon. Wrist splint and pharmacotherapy were used during 2 weeks after surgery. Sleep quality and severity of symptoms were evaluated at 1, 3, and 12 months postoperatively by the PSQI and Boston carpal tunnel syndrome questionnaire.

The PSQI is a self-rated questionnaire that can assess sleep quality and disturbances over a 1 -month period. ${ }^{16}$ It consists of 19 individual items which generate the following seven components: sleep quality, sleep latency, sleep duration, habitual sleep efficiency, sleep disturbances, use of sleeping medication, and daytime dysfunction. Each component is scored from zero to three, with zero representing no problem and three representing the worst sleep quality. The total score of these seven components yields the global PSQI score. The higher the score, the worse sleep quality that the patient complains of. Since all patients did not use pharmacological or medical support for sleeping problems, all were given a score of zero for the sixth component (use of sleeping medication) and this component was excluded from the analysis.

The Boston carpal tunnel syndrome questionnaire, ${ }^{17}$ also called the Levine-Katz Questionnaire, is also a selfadministered questionnaire which assesses the severity of symptoms and functional status in patients with CTS. It has 19 questions: 11 dealing with symptom and eight with function. Each question is scored from one (the mildest) to five (the most severe). A higher score indicates more severity of the patient's symptom and function.

\section{Statistical Analysis}

Patients' characteristics and study outcomes (PSQI and Boston scores) were summarized by counts and percentages for categorical variables, and median and interquartile range (IQR) for continuous variables. The longitudinal measurements of the outcomes were presented graphically for males and females. We compared the differences of the scores between each time-point before and after CTR using Wilcoxon signed rank test. Correlation between PSQI and Boston symptom score and Boston function score were analyzed by Spearman's correlation coefficients. All tests were two-sided and statistical significance was defined when $p$-value was $<0.05$. All analyses were performed using the statistical software $R$ version 3.6.3 ( $R$ Foundation for Statistical Computing, Vienna, Austria).

\section{Results}

A total of 33 patients were included in the study with females predominating (27 cases, $82 \%$ ) and median age of 51 years (range: 33-71). Median duration of confirmed CTS before undergoing the surgery was 12 months (range: 5-36), whereas median duration of having sleep disorder was 6 months (range: 2-12). There was no patient with hypothyroidism or rheumatoid arthritis. All patients had received conservative treatment with the median preoperative duration being 8 months (range: 3-18). Eight patients (24\%) underwent CTR in both hands (-Table $\mathbf{1}$ ).

Median global PSQI score was 12 (range: 8-16) before surgery and decreased to 9 (range: 6-15) at 1 month, 7 (range: 5-10) at 3 months, and 1 (range: 0-9) at 12 months postoperatively, with significant differences (-Table 2, - Fig. 1). The analysis of each PSQI component also showed significant improvement in all components after surgery (-Table 2 ). With regard to the Boston symptom and function scores, the results were similar, with a significant improvement in the hand symptom and function scores from before to after surgery 
Table 1 Patients' characteristics

\begin{tabular}{|l|l|}
\hline & $\begin{array}{l}\text { All patients } \\
(\boldsymbol{n}=33)\end{array}$ \\
\hline Sex female, $n(\%)$ & $27(82)$ \\
\hline Age (years), median (IQR) & $51(45-57)$ \\
\hline $\begin{array}{l}\text { Duration of CTS before surgery (months), } \\
\text { median (IQR) }\end{array}$ & $12(12-15)$ \\
\hline $\begin{array}{l}\text { Duration of sleep disorder before } \\
\text { surgery (months), median (IQR) }\end{array}$ & $6(5-7)$ \\
\hline $\begin{array}{l}\text { Receiving conservative treatment previously, } \\
\text { median (IQR) }\end{array}$ & $33(100)$ \\
\hline $\begin{array}{l}\text { Duration of conservative treatment before } \\
\text { surgery (months), median (IQR) }\end{array}$ & $8(6-10)$ \\
\hline Hypothyroidism, $n$ (\%) & $0(0)$ \\
\hline Rheumatoid arthritis, $n$ (\%) & $0(0)$ \\
\hline Hand undergoing surgery, $n(\%)$ & $14(43)$ \\
\hline Right hand & $11(33)$ \\
\hline Left hand & $8(24)$ \\
\hline Both hands & \\
\hline
\end{tabular}

Abbreviations: CTS, carpal tunnel syndrome; IQR, interquartile range.

(-Table 2, -Fig. 1). The improvement of these scores were similar in males and females (-Fig. $\mathbf{1}$ ).

The PSQI global scores had a significant and highly positive correlation with the Boston symptom and function scores. The correlation was consistent from before to after surgery, with the Spearman's correlation coefficients being $>0.60$ in all analyses (-Fig. 2).

\section{Discussion}

This study shows consistent improvements of sleep quality as well as the symptoms and functions of the hand at 1 to 12 months after CTR, according to the PSQI and Boston symptom and function scores. The study also demonstrates
审 Male 审 Female
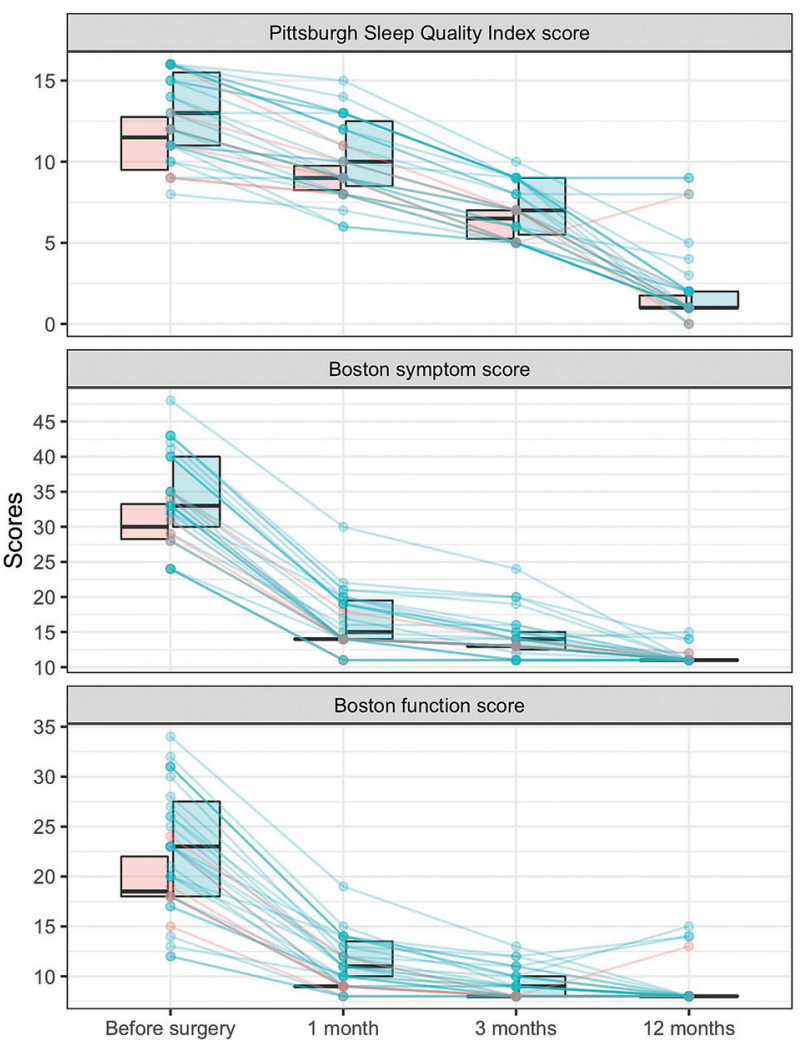

Fig. 1 Pittsburgh sleep quality index and Boston test scores over time. In each plot, scores are presented by time-points before and after surgery 1,3 , and 12 months and are colored separately for males and females. The line inside each box is the median, and the upper and lower margins of each box represent the interquartile range. The points and lines represent the actual scores of each individual patient at each time-point.

that sleep quality highly correlates with the hand symptom and function scores. As good sleep quality is important and can reduce the risk of stress, depression, hypertension, overweight and obesity, it is important for patients to undergo CTR when having indication.

Table 2 Outcomes assessment

\begin{tabular}{|l|l|l|l|l|l|l|l|}
\hline & Before surgery & $\mathbf{1}$ month & $p^{0-1}$ & 3 months & $p^{1,2}$ & 12 months & $p^{2,3}$ \\
\hline Sleep quality & $2(2-3)$ & $2(2-2)$ & $<0.001$ & $2(1-2)$ & $<0.001$ & $0(0-1)$ & $<0.001$ \\
\hline Sleep latency & $2(2-3)$ & $2(2-3)$ & 0.180 & $2(1-2)$ & $<0.001$ & $0(0-1)$ & $<0.001$ \\
\hline Sleep duration & $2(2-3)$ & $1(1-2)$ & $<0.001$ & $1(1-1)$ & $<0.001$ & $1(1-1)$ & 0.037 \\
\hline Habitual sleep efficiency & $2(2-3)$ & $1(1-2)$ & $<0.001$ & $0(0-1)$ & $<0.001$ & $0(0-0)$ & 0.011 \\
\hline Sleep disturbances & $1(1-1)$ & $1(1-1)$ & - & $1(1-1)$ & - & $0(0-0)$ & $<0.001$ \\
\hline Daytime dysfunction & $3(2-3)$ & $2(2-3)$ & 0.066 & $2(1-2)$ & $<0.001$ & $0(0-0)$ & $<0.001$ \\
\hline PSQI global score & $12(11-15)$ & $9(8-12)$ & $<0.001$ & $7(5-9)$ & $<0.001$ & $1(1-2)$ & $<0.001$ \\
\hline Boston symptom score & $33(29-40)$ & $14(14-19)$ & $<0.001$ & $13(13-15)$ & $<0.001$ & $11(11-11)$ & $<0.001$ \\
\hline Boston function score & $23(18-26)$ & $11(9-13)$ & $<0.001$ & $9(8-10)$ & $<0.001$ & $8(8-8)$ & 0.170 \\
\hline
\end{tabular}

Abbreviations: IQR, interquartile range; PSQI, Pittsburgh sleep quality index.

Note: Summary statistics are median (IQR). $p^{0-1}$ is for testing change from before surgery to 1 month. $p^{1,2}$ is for testing change from 1 to 3 months. $p^{2,3}$ is for testing change from 3 to 12 months. All $p$-values are based on Wilcoxon signed rank test. 

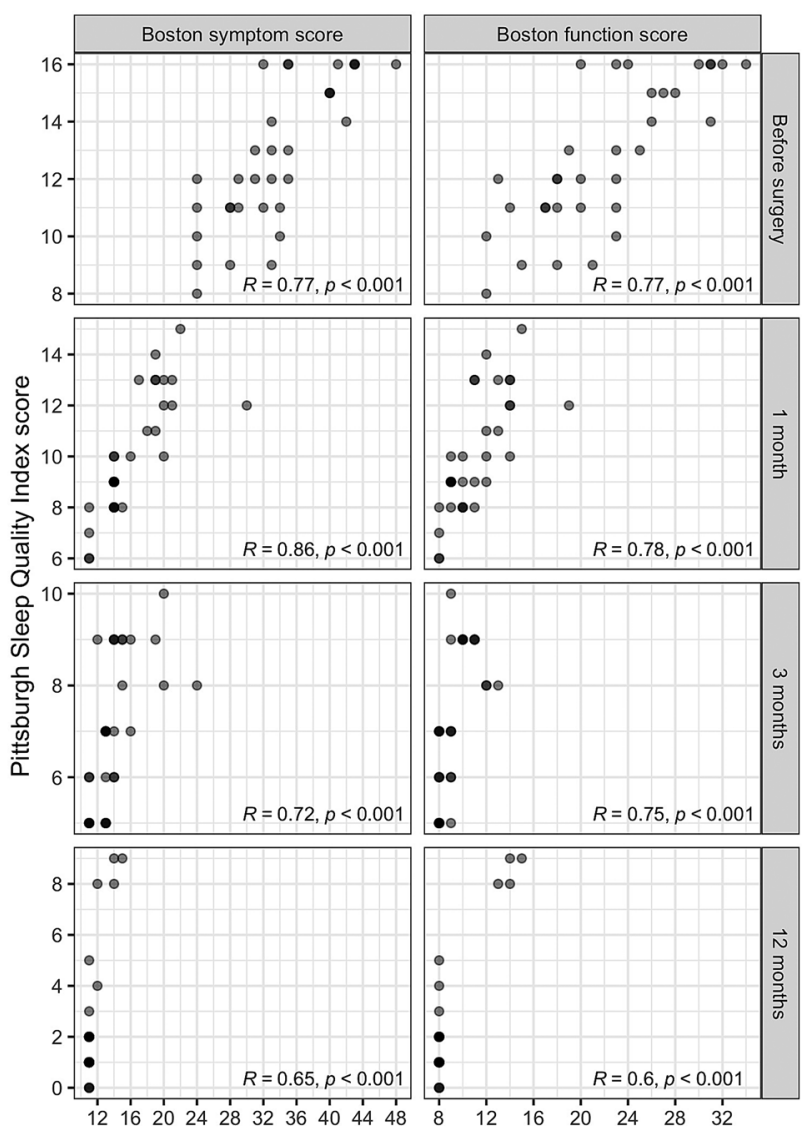

Fig. 2 Correlation between Pittsburgh sleep quality index (PSQI) and Boston test scores The plots represent the correlation between PSQI score and Boston symptom score (in the left column), and Boston function score (in the right column), at the four time-points (before surgery, after surgery 1,3 , and 12 months, from top to bottom, respectively). Each gray point represents for each patient. Spearman's correlation coefficient and $p$-value are shown in the bottom right corner of each plot.

Sleep symptoms are frequent in patients with CTS and cause a huge impact on their quality of life, but they have just got more attention since several years ago. The seriousness of sleep disorder is thought to associate with the grade of nerve entrapment. ${ }^{5}$ This is somehow proved in our study by the strong positive correlation between the PSQI score and the Boston symptom and function scores: the more severe symptom is associated with the worse sleep quality. Although both questionnaires are subjective, the consistent results of these correlations at multiple time-points before and after surgery would minimize the potential subjective bias. In addition, other studies also reported the significant correlation between CTS symptom and functional severity with sleep quality, ${ }^{6,12}$ which consolidate the evidence of the association between CTS symptoms and sleep disturbance. Therefore, handling the symptoms is essential in order to solve the sleep problem of patients with CTS. In patients with long time of having CTS, especially those with poor sleep quality due to CTS, most conservative treatments do not work well and surgery is the only choice. Indeed, CTR has shown its effectiveness in CTS by the significant improvement in the hand's symptoms and functions as well as sleep quality..$^{8-13,18}$ In our study, the early improvements are more marked for the symptoms and functions of the hand, whereas the sleep quality improved more slowly. However, our study and others have a relatively short follow-up period (less than 1 year), so long-term outcomes of patients are still lacking, as in our results, some patients tend to be worse from 3 to 12 months after the surgery, with respect to both the PSQI and Boston symptom and function scores.

Limitations of the study included lack of a control group without surgery and potential selection bias due to a singlecentre design with single surgeon's practice. A comparable multicenter study would confirm and generalize the results better. However, a control group with similar disease severity is hard to get because surgery is indicated for patients with pain unresponsive to conservative treatment. Second, recall bias, which is inherent in all questionnaires, maybe present in this study. However, the consistent improvement of the scores via assessing all patients several times before and after surgery could minimize this potential bias. Third, sleep quality was not evaluated using polysomnography. Therefore, obstructive sleep apnea, which was reported to have higher frequency of CTS, ${ }^{19}$ could not be excluded in this study.

In conclusion, surgical decompression significantly improves sleep quality and the symptom and function of the hand in patients with CTS and poor sleep quality. These improvements start right after the surgery and remain until 12 months. The study also confirms that the PSQI and Boston symptom and function questionnaires are applicable instruments to quantify the results after CTR. More studies with long-term follow-up are needed, as there is lack of longterm results of the surgery in the treatment of CTS.

\section{Conflict of Interest}

None declared.

\section{References}

1 Paget J. The first description of carpal tunnel syndrome. J Hand Surg Eur Vol 2007;32(02):195-197

2 Padua L, Coraci D, Erra C, et al. Carpal tunnel syndrome: clinical features, diagnosis, and management. Lancet Neurol 2016;15 (12):1273-1284

3 Patel JN, McCabe SJ, Myers J. Characteristics of sleep disturbance in patients with carpal tunnel syndrome. Hand (N Y) 2012;7(01): 55-58

4 Gaspar MP, Kane PM, Jacoby SM, Gaspar PS, Osterman AL. Evaluation and management of sleep disorders in the hand surgery patient. J Hand Surg Am 2016;41(10):1019-1026

5 Lehtinen I, Kirjavainen T, Hurme M, Lauerma H, Martikainen K, Rauhala E. Sleep-related disorders in carpal tunnel syndrome. Acta Neurol Scand 1996;93(05):360-365

6 Patel A, Culbertson MD, Patel A, et al. The negative effect of carpal tunnel syndrome on sleep quality. Sleep Disord 2014; 2014:962746

7 Graham B, Regehr G, Naglie G, Wright JG. Development and validation of diagnostic criteria for carpal tunnel syndrome. J Hand Surg Am 2006;31(06):919-924 
8 Tulipan JE, Kim N, Abboudi J, et al. Prospective evaluation of sleep improvement following carpal tunnel release surgery. J Hand Surg Am 2017;42(05):390.e1-390.e6

9 Rubin G, Orbach H, Rinott M, Rozen N. The effectiveness of splinting and surgery on sleep disturbance in carpal tunnel syndrome. J Hand Surg Eur Vol 2018;43(03):286-289

10 Erickson J, Polatsch D, Beldner S, Melamed E. An assessment of sleep disturbance in patients before and after carpal tunnel release. J Hand Surg Asian Pac Vol 2019;24(02):144-146

11 Gaspar MP, Osterman MN, Shin EK, Osterman AL, Kane PM. Sleep disturbance and response to surgical decompression in patients with carpal tunnel syndrome: a prospective randomized pilot comparison of open versus endoscopic release. Acta Biomed 2019;90(01):92-96

12 Okkesim CE, Serbest S, Tiftikçi U, Çirpar M. Prospective evaluation of preoperative and postoperative sleep quality in carpal tunnel release. J Hand Surg Eur Vol 2019;44(03):278-282

13 Niedermeier SR, Pettit RJ, Frantz TL, Colvell K, M Awan H. Early postoperative improvement in sleep and pain after carpal tunnel release. Hand (N Y) 2020;15(03):311-314
14 Keith MW, Masear V, Chung K, et al. Diagnosis of carpal tunnel syndrome. J Am Acad Orthop Surg 2009;17(06):389-396

15 Graham B, Peljovich AE, Afra R, et al. The American Academy of Orthopaedic Surgeons Evidence-Based Clinical Practice Guideline on: Management of Carpal Tunnel Syndrome. J Bone Joint Surg Am 2016;98(20):1750-1754

16 Buysse DJ, Reynolds CF III, Monk TH, Berman SR, Kupfer DJ. The Pittsburgh Sleep Quality Index: a new instrument for psychiatric practice and research. Psychiatry Res 1989;28(02):193-213

17 Levine DW, Simmons BP, Koris MJ, et al. A self-administered questionnaire for the assessment of severity of symptoms and functional status in carpal tunnel syndrome. J Bone Joint Surg Am 1993;75(11):1585-1592

18 Trouw AG, Patel A, Yang A, Jauregui J, Caligiuri D, Choueka J. Improvement in sleep quality after carpal tunnel release. J Long Term Eff Med Implants 2018;28(01):55-61

19 Bilgin Topçuoğlu Ö, Oruç Ö, Saraç S, Çetintaş Afşar G, Uluç KCarpal tunnel syndrome in obstructive sleep apnea patients. Noro Psikiyatri Arsivi 2017;54(04):307-311 